\title{
RANCANG BANGUN ALAT MONITORING RADIOAKTIVITAS KADAR POLUSI UDARA
}

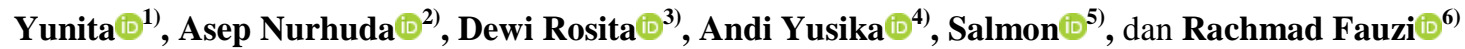 \\ 1,4,5,6 STMIK Widya Cipta Dharma \\ ${ }^{2}$ Teknologi Rekayasas Perangkat Lunak, Politeknik Pertanian Negeri Samarinda \\ ${ }^{3}$ Pendikikan Komputer, Universitas Mulawarman \\ 1,4,5,6Jl. M. Yamin No.25, Samarinda, 75123 \\ ${ }^{2} \mathrm{Jl}$. Samratulangi, Samarinda, 75131 \\ ${ }^{3} \mathrm{Jl}$. Muara Pahu Kampus Gunung Kelua Samarin, 75123 \\ E-mail : yunita@wicida.id ${ }^{1)}$, acep.noor@gmail.com ${ }^{2}$, dew.rosita@gmail.com ${ }^{3)}$, andi@wicida.id ${ }^{4)}$, salmon@wicida.id ${ }^{5)}$, \\ fauzi2507@gmail.com ${ }^{6}$
}

\begin{abstract}
ABSTRAK
Di era modern seperti saat ini, penggunaan sistem pendeteksi kadar udara semakin pesat, sistem kontrol pada umumnya membantu masyarakat untuk mengetahui kualitas polusi udara, dalam hal ini sistem yang di gunakan adalah mikrokontroler yang di rangkai dengan sensor karbon monoksida, sensor debu dan sensor suhu sebagai input dan perangkat-perangkat pendukung lainnya. Penelitian ini menggunakan metode observasi dan prototype yaitu salah satu metode pengembangan perangkat lunak yang banyak di gunakan. Dengan metode prototype ini pengembang dan pelanggan dapat saling berinteraksi selama proses pembuatan sistem. Observasi yaitu teknik pengumpulan data dimana peneliti melakukan pengamatan dan pencatatan secara sistematik terhadap permasalahan yang berhubungan dengan masalah yang akan diteliti. Penelitian ini di harapkan dapat meningkatkan kemudahan bagi pengguna dari sistem pendeteksi kadar udara menggunakan sensor karbon monoksida, sensor debu dan sensor suhu input-nya. Saat sistem menyala semua sensor akan mengalibrasi dalam waktu beberapa detik. Selanjutnya semua sensor akan mendeteksi kadar udara sesuai dengan fungsinya. Sinyal analog yang di hasilkan dari sensor saat mendeteksi akan masuk melalui pin Analog to Digital Converter (ADC) sistem minimum Arduino.
\end{abstract}

Kata Kunci: Kadar Udara, Polusi, Prototype, Mikrokontroler, Arduino.

\section{PENDAhULUAN}

Teknologi merupakan suatu sarana yang digunakan manusia untuk memenuhi kebutuhan mereka, beberapa teknologi saat ini merupakan perkembangan dari teknologi zaman dahulu yang sering digunakan dalam kegiatan sehari - hari (Dinata, 2016). Oleh karena itu, perkembangan teknologi yang berubah menjadi teknologi masa kini telah berkembang pesat. Seiring waktu pun teknologi komputer yang dikembangkan bukan hanya sekadar mesin penghitung tapi juga mesin yang dapat memproses data (Artanto, 2012).

Saat ini kualitas udara memperlihatkan kondisi yang sangat memprihatinkan. Banyak sekali kegiatan manusia yang dibuat adalah menghasilkan pencemaran. Salah satunya adalah pencemaran udara, seperti industri, transportasi, dan perumahan. Akan tetapi ada juga sebab dari sumber pencemaran udara lainnya yaitu aktivitas alam seperti meletusnya sebuah gunung, munculnya gas alam yang beracun, dan termasuk terjadinya kebakaran hutan (Atmaja, 2018).

Oleh karena itu, kualitas udara menjadi tidak sehat dan berdampak negatif terhadap kesehatan manusia karena terpapar oleh polusi. Kesehatan manusia sangat rentan oleh udara, terutama udara di tempat terbuka. Kualitas udara yang buruk dapat menyebabkan penyakit pada manusia (Warsiti dkk, 2020). Udara yang tercemar dapat ditemui di kota besar, jalanan yang padat, dan kawasan industri. Oleh sebab itu, dilakukan kegiatan yaitu pengukuran kualitas udara. Dengan adanya pengukuran kualitas udara maka dapat diketahui udara sekitar tercemar atau tidak (Halizah dkk, 2021).

Sehubungan dengan hal diatas inilah, tim peneliti berkeinginan untuk membangun sebuah alat pendeteksi polusi udara dengan menggunakan Arduino Uno. Judul yang akan diangkat untuk penelitian ini adalah "Rancang Bangun Alat Monitoring Radioaktivitas Kadar Polusi Udara". Tim peneliti bermaksud untuk membuat sebuah alat untuk mendeteksi polusi udara menggunakan sensor MQ-7 sebagai sensor karbon monoksida, sensor GP2Y1010AU0F sebagai sensor debu, dan sensor DHT11 sebagai sensor suhu yang dikendalikan oleh Arduino dan ditampilkan pada sebuah LCD. Tim peneliti berharap dapat membuat lebih praktis prinsip kerjanya dan membantu kemudahan akan informasi kualitas udara. 


\section{RUANG LINGKUP}

Dalam penelitian ini permasalahan mencakup:

1. Modul mikrokontroler yang digunakan adalah Arduino Uno.

2. Pengolahan data input perangkat lunak hanya menggunakan software Arduino IDE.

3. Hanya mendeteksi kadar karbon monoksida, debu, dan suhu.

4. Display atau penampil nilai data hanya menggunakan LCD.

\section{BAHAN DAN METODE}

Dalam penelitian ini diperlukan suatu konsep dalam merumuskan definisi yang menunjang kegiatan penelitian, baik teori dasar maupun teori umum.

\subsection{Mikrokontroler}

Mikrokontroler adalah suatu IC yang didesain atau dibentuk dengan kepadatan yang sangat tinggi, dimana semua bagian yang diperlukan untuk suatu controller sudah dikemas dalam satu keping, biasanya terdiri dari Central Processing Unit (CPU), Random Access Memory (RAM), EEPROM/EPROM/PROM/ROM, I/O, Serial \& Parallel, Timer, Interrupt Controller dan berfungsi sebagai pengontrol rangkaian elektronik serta umumnya dapat menyimpan program di dalamnya (Kusumah,dkk. 2018) dan (Susilo, 2018). Seperti umumnya komputer, mikrokontroler adalah alat yang mengerjakan instruksi instruksi yang diberikan kepadanya. Artinya, bagian terpenting dan utama dari suatu sistem terkomputerisasi adalah program itu sendiri yang dibuat oleh seorang programmer. Program ini menginstruksikan komputer untuk melakukan jalinan yang panjang dari aksi - aksi sederhana untuk melakukan tugas yang lebih kompleks yang diinginkan oleh programmer (Kusumaningtyas, dkk. 2014).

\subsection{Arduino}

Arduino adalah sistem purwarupa elektronika (electronic prototyping platform) berbasis open-source yang fleksibel dan mudah digunakan baik dari sisi perangkat keras/hardware maupun perangkat lunak/software (McRoberts, 2011). Arduino didefinisikan sebagai sebuah platform elektronik yang open source, berbasis pada software dan hardware yang fleksibel dan mudah digunakan, yang ditujukan untuk seniman, desainer, hobby dan setiap orang yang tertarik dalam membuat sebuah objek atau lingkungan yang interaktif (Kadir, 2016).

\subsection{Sensor MQ-7}

MQ 7 merupakan sensor gas yang digunakan dalam peralatan untuk mendeteksi gas karbon monoksida (CO) dalam kehidupan sehari-hari, industri atau mobil. Sensor MQ7 memiliki sensitivitas tinggi dan respon cepat terhadap gas karbon monoksida dan keluaran dari sensor MQ7 berupa sinyal analog dan membutuhkan tegangan DC sebesar 5Volt. Fitur dari sensor gas MQ7 ini adalah mempunyai sensitivitas yang tinggi terhadap karbon monoksida (CO), stabil, dan berumur panjang. (Wasista dkk, 2019).

\subsection{Sensor GP2Y1010AU0F}

GP2Y1010AU0F Optical Dust Sensor merupakan sensor debu yang berbasis inframerah dengan menerapkan prinsip kerja cahaya dicerminkan pada partikel yang melewati sensor (Orlowski, 2020). Cara kerja sensor ini adalah mendeteksi debu atau partikel yang melewati LED dan sensor photodiode di dalam modul, perubahan intensitas yang dideteksi oleh sensor photodiode akan merepresentasikan densitas debu (Sakti, 2017). Cahaya dicerminkan pada partikel melewati keseluruhan permukaan, kemudian oleh photodiode diubah menjadi tegangan. Tegangan harus diperkuat untuk dapat membaca perubahan. Output dari sensor adalah tegangan analog sebanding dengan kepadatan debu yang terukur, dengan sensitivitas $0.5 \mathrm{~V} / 0.1 \mathrm{mg} / \mathrm{m} 3$, artinya setiap $0,1 \mathrm{mg} / \mathrm{m} 3$ kepadatan debu yang terukur, maka tegangannya naik sebesar $0,5 \mathrm{~V}$ (Dinata, 2016).

\subsection{Metode Prototyping}

Prototyping merupakan metode pengembangan perangkat lunak, yang berupa model fisik kerja sistem dan berfungsi sebagai versi awal dari sistem (Tarigan, 2016). Dengan metode prototyping ini akan dihasilkan prototype sistem sebagai perantara pengembang dan pengguna agar dapat berinteraksi dalam proses kegiatan pengembangan sistem informasi. Agar proses pembuatan prototype ini berhasil dengan baik adalah dengan mendefinisikan aturan-aturan pada tahap awal, yaitu pengembang dan pengguna harus satu pemahaman bahwa prototype dibangun untuk mendefinisikan kebutuhan awal. Prototype akan dihilangkan atau ditambahkan pada bagiannya sehingga sesuai dengan perencanaan dan analisis yang dilakukan oleh pengembang sampai dengan uji coba dilakukan secara simultan seiring dengan proses pengembangan (Kaunang dik, 2021). Langkah-langkah dalam prototyping adalah sebagai berikut:

1. Pengumpulan kebutuhan.

2. Proses desain yang cepat.

3. Membangun prototype.

4. Evaluasi dan perbaikan.

\section{PEMBAHASAN}

Dalam penelitian ini diperlukan suatu perancangan sistem/aplikasi untuk menunjang kegiatan penelitian dengan baik dan hasil implementasi.

\subsection{Pengumpulan Kebutuhan dan Desain Alat}

Perancangan perangkat keras merupakan gambaran dari desain alat pendeteksi kadar udara yang akan dibuat. Gambar 1 Desain Perangkat Keras Keterangan:
1. Arduino Uno
2. Sensor MQ-7
3. Sensor GP2Y1010AU0F 
4. Sensor DHT11

5. Resistor

6. LCD
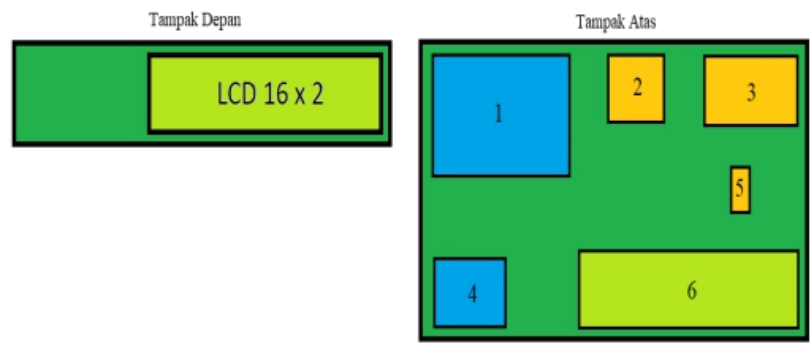

Gambar 1 Desain Perangkat Keras

Gambar 2 Blok diagram rangkaian bagian terpisah dari rangkaian yang saling terhubung. Di dalam blok rangkaian input diproses hingga menghasilkan sinyal output.

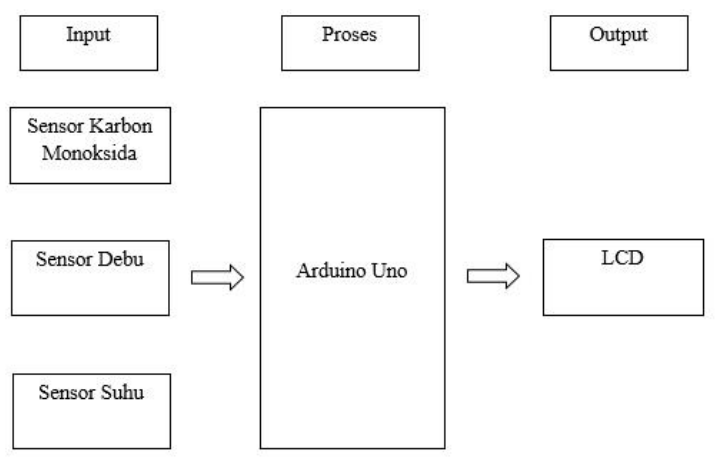

Gambar 2. Blok Diagram

Gambar 3 ini dinyatakan dengan simbol dan setiap simbol menggambarkan proses tertentu. Dengan adanya flowchart urutan proses kegiatan menjadi lebih jelas.

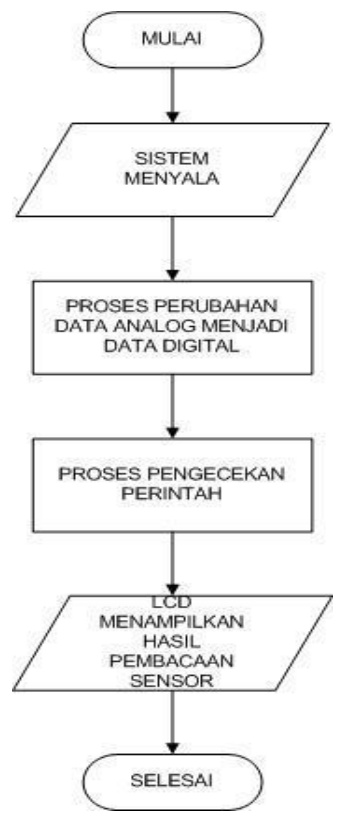

Gambar 3. Flowchart Sistem

\subsection{Membangun Prototype}

Hasil membangun prototype berupa perangkat keras sebuah alat monitoring radioaktivitas kadar polusi.

1. Membangun Prototype.

Alat pendeteksi kadar udara ini dibangun untuk dapat bekerja secara kontinu. Terdapat sensor MQ-7, sensor GP2Y1010AU0F dan sensor DHT11. Masing-masing sensor akan mendeteksi sesuai dengan fungsinya, setelah terdeteksi data dikirimkan ke mikrokontroler Arduino Uno. Selanjutnya nilai pembacaan sensor akan ditampilkan pada LCD. Gambar 4 adalah perakitan pada semua perangkat keras yang telah dikumpulkan lalu diprogram menggunakan Arduino IDE.

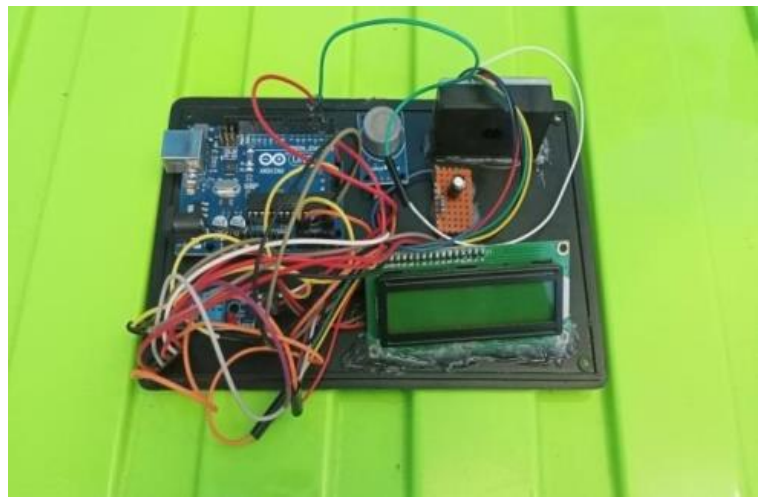

Gambar 4. Alat Pendeteksi Kadar Polusi

2. Pengujian Black Box

Tabel 1 adalah hasil pengujian melakukan ujian sistem pada keseluruhan alat ukur ini adalah user.

Tabel 1. Pengujian Black Box

\begin{tabular}{|c|c|c|c|c|}
\hline No & Kasus Uji & $\begin{array}{c}\text { Skenario } \\
\text { Uji }\end{array}$ & $\begin{array}{l}\text { Hasil yang } \\
\text { Diharapkan }\end{array}$ & Ket. \\
\hline 1 & Sensor MQ-7 & $\begin{array}{c}\text { Sensor } \\
\text { membaca } \\
\text { inputan } \\
\text { gas CO }\end{array}$ & $\begin{array}{c}\text { Sensor } \\
\text { berhasil } \\
\text { membaca } \\
\text { inputan }\end{array}$ & $\begin{array}{c}{[\mathrm{x}]} \\
\text { Diterima } \\
{[]} \\
\text { Ditolak }\end{array}$ \\
\hline 2 & $\begin{array}{c}\text { Sensor } \\
\text { GP2Y1010A } \\
\text { U0F }\end{array}$ & $\begin{array}{c}\text { Sensor } \\
\text { mendeteksi } \\
\text { inputan } \\
\text { debu }\end{array}$ & $\begin{array}{l}\text { Sensor } \\
\text { berhasil } \\
\text { membaca } \\
\text { inputan }\end{array}$ & $\begin{array}{c}{[\mathrm{x}]} \\
\text { Diterima } \\
{[]} \\
\text { Ditolak }\end{array}$ \\
\hline 3 & LCD & $\begin{array}{c}\text { LCD } \\
\text { menampil } \\
\text { kan hasil } \\
\text { inputan } \\
\text { sensor }\end{array}$ & $\begin{array}{c}\text { LCD } \\
\text { berhasil } \\
\text { menampil } \\
\text { kan hasil } \\
\text { inputan }\end{array}$ & $\begin{array}{c}\mathrm{x}] \\
\text { Diterima } \\
{[]} \\
\text { Ditolak }\end{array}$ \\
\hline 4 & $\begin{array}{c}\text { Arduino } \\
\text { Mega WiFi }\end{array}$ & $\begin{array}{l}\text { Wifi } \\
\text { membuat } \\
\text { koneksi } \\
\text { terhadap } \\
\text { Blynk }\end{array}$ & $\begin{array}{c}\text { Wifi } \\
\text { berhasil } \\
\text { membuat } \\
\text { koneksi }\end{array}$ & $\begin{array}{c}{[\mathrm{x}]} \\
\text { Diterima } \\
{[]} \\
\text { Ditolak }\end{array}$ \\
\hline
\end{tabular}




\subsection{Evaluasi Dan Perbaikan}

Pengujian Beta dilakukan dari sisi end user, baik seorang maupun beberapa orang, dimana pihak pengembang tidak berada bersama para end user tersebut. Atau dengan kata lain, uji coba beta dilakukan dalam lingkungan yang tidak terkontrol oleh pengembang. Pengujian beta dalam hal ini dilakukan dengan tujuan untuk mengetahui sejauh mana kualitas perangkat yang akan dibangun, apakah sesuai dengan apa yang diharapkan dengan cara memberikan kuesioner yang dilakukan kepada 10 responden sebagai user (pengguna). Pertama kita menentukan jumlah skor jawaban responden terhadap tiap soal. Dengan menggunakan (1)

$$
\mathrm{P}=\sum \mathrm{Si} \times \mathrm{Ri}
$$

Keterangan (1)

$$
\begin{array}{ll}
\mathrm{P} & =\begin{array}{l}
\text { Hasil jumlah skor (bobot) jawaban } \\
\text { responden. }
\end{array} \\
\mathrm{Si} & =\text { Skor untuk jawaban responden ke-i } \\
\mathrm{Ri} & =\text { Banyaknya responden untuk jawaban ke-i }
\end{array}
$$

Setelah menentukan jumlah skor, lalu hitung nilai persentase, menggunakan (2)

$$
\mathrm{Y}=(\mathrm{P} / \mathrm{Q}) \times 100 \%
$$

Keterangan (2)

$$
\begin{aligned}
& \mathrm{P} \quad=\text { Hasil jumlah skor hasil jawaban } \\
& \text { responden. } \\
& \mathrm{Q} \quad=\text { Nilai tertinggi yang dikalikan dengan } \\
& \text { jumlah sampel. } \\
& \mathrm{Y} \quad=\text { Nilai persentase }
\end{aligned}
$$

Nilai persentase pembobotan beta dapat dilihat pada tabel 2.

\begin{tabular}{|c|c|c|c|c|}
\hline Jawaban & Skor & Responden & $\begin{array}{c}\text { Jumlah } \\
\text { Skor }\end{array}$ & $\begin{array}{c}\text { Nilai } \\
\text { Persentase }\end{array}$ \\
\hline $\begin{array}{l}\text { Sangat } \\
\text { Membantu }\end{array}$ & 5 & 7 & 35 & \multirow{6}{*}{$\begin{array}{c}(47 / 50) \times 100 \% \\
=94 \%\end{array}$} \\
\hline Membantu & 4 & 3 & 12 & \\
\hline $\begin{array}{l}\text { Cukup } \\
\text { Membantu }\end{array}$ & 3 & 0 & 0 & \\
\hline $\begin{array}{l}\text { Kurang } \\
\text { Membantu } \\
\end{array}$ & 2 & 0 & 0 & \\
\hline $\begin{array}{l}\text { Tidak } \\
\text { Membantu }\end{array}$ & 1 & 0 & 0 & \\
\hline Jumlah & & 10 & 47 & \\
\hline
\end{tabular}

Tabel 2. Nilai Persentase

\begin{tabular}{|c|c|}
\hline Jawaban & Nilai Persentase \\
\hline Sangat Membantu & $81 \%-100 \%$ \\
\hline Membantu & $61 \%-80 \%$ \\
\hline Cukup Membantu & $41 \%-60 \%$ \\
\hline Kurang Membantu & $21 \%-40 \%$ \\
\hline Tidak Membantu & $0 \%-20 \%$ \\
\hline
\end{tabular}

Hasil pengujian beta pada tingkat sensitivitas sensor. Dengan pertanyaan sebagai berikut: Bagaimana dengan tingkat sensitivitas pada masing-masing sensor? Berdasarkan tabel 3 hasil persentase adalah 94\%. Maka dapat disimpulkan bahwa tingkat sensitivitas sensor ini dinyatakan sangat membantu.
Tabel 3. Hasil pengujian beta pada tingkat sensitivitas sensor

\begin{tabular}{|c|c|c|c|c|}
\hline Jawaban & Skor & Responden & $\begin{array}{c}\text { Jumlah } \\
\text { Skor }\end{array}$ & $\begin{array}{c}\text { Nilai } \\
\text { Persentase }\end{array}$ \\
\hline $\begin{array}{l}\text { Sangat } \\
\text { Membantu }\end{array}$ & 5 & 10 & 50 & \multirow{6}{*}{$\begin{aligned} &(50 / 50) \\
& \times 100 \% \\
&= 100 \%\end{aligned}$} \\
\hline Membantu & 4 & 0 & 0 & \\
\hline $\begin{array}{l}\text { Cukup } \\
\text { Membantu }\end{array}$ & 3 & 0 & 0 & \\
\hline $\begin{array}{l}\text { Kurang } \\
\text { Membantu }\end{array}$ & 2 & 0 & 0 & \\
\hline $\begin{array}{l}\text { Tidak } \\
\text { Membantu }\end{array}$ & 1 & 0 & 0 & \\
\hline Jumlah & & 10 & 50 & \\
\hline
\end{tabular}

Hasil pengujian beta pada kecepatan proses kerja sensor. Dengan pertanyaan sebagai berikut: Bagaimana tingkat kecepatan sensor dalam mendeteksi kadar udara di lingkungan sekitar? Berdasarkan tabel 4 hasil persentase adalah $100 \%$. Maka dapat disimpulkan bahwa proses kecepatan kerja sensor dinyatakan sangat membantu.

Tabel 4. Hasil pengujian beta pada proses kecepatan kerja sensor

Hasil pengujian beta pada tampilan output. Dengan pertanyaan sebagai berikut: Bagaimana output pada alat ini. Apakah membantu menyajikan informasi dari pembacaan nilai sensor? Berdasarkan tabel 5 hasil persentase adalah $68 \%$. Maka dapat disimpulkan bahwa tampilan output dinyatakan membantu. 
Tabel 5. Hasil pengujian beta pada tampilan output

\begin{tabular}{|c|c|c|c|c|}
\hline Jawaban & Skor & Responden & $\begin{array}{c}\text { Jumlah } \\
\text { Skor }\end{array}$ & $\begin{array}{c}\text { Nilai } \\
\text { Persentase }\end{array}$ \\
\hline $\begin{array}{l}\text { Sangat } \\
\text { Membantu }\end{array}$ & 5 & 0 & 0 & \multirow{6}{*}{$\begin{array}{l}(34 / 50) \\
\times 100 \% \\
=68 \%\end{array}$} \\
\hline Membantu & 4 & 4 & 16 & \\
\hline $\begin{array}{l}\text { Cukup } \\
\text { Membantu }\end{array}$ & 3 & 6 & 18 & \\
\hline $\begin{array}{l}\text { Kurang } \\
\text { Membantu }\end{array}$ & 2 & 0 & 0 & \\
\hline $\begin{array}{l}\text { Tidak } \\
\text { Membantu }\end{array}$ & 1 & 0 & 0 & \\
\hline Jumlah & & 10 & 34 & \\
\hline
\end{tabular}

Hasil pengujian beta pada rancangan prototype. Dengan pertanyaan sebagai berikut: Bagaimana tentang rancangan dari prototype yang telah dibangun ? Berdasarkan tabel 6 hasil persentase adalah 70\%. Maka dapat disimpulkan bahwa rancangan prototype dinyatakan membantu.

Tabel 6. Hasil pengujian beta pada rancangan prototype

\begin{tabular}{|c|c|c|c|c|}
\hline Jawaban & Skor & Responden & $\begin{array}{c}\text { Jumlah } \\
\text { Skor } \\
\end{array}$ & $\begin{array}{c}\text { Nilai } \\
\text { Persentase } \\
\end{array}$ \\
\hline $\begin{array}{l}\text { Sangat } \\
\text { Membantu }\end{array}$ & 5 & 0 & 0 & \multirow{6}{*}{$\begin{array}{l}(35 / 50) \\
\times 100 \% \\
=70 \%\end{array}$} \\
\hline Membantu & 4 & 5 & 20 & \\
\hline $\begin{array}{l}\text { Cukup } \\
\text { Membantu }\end{array}$ & 3 & 5 & 15 & \\
\hline $\begin{array}{l}\text { Kurang } \\
\text { Membantu }\end{array}$ & 2 & 0 & 0 & \\
\hline $\begin{array}{l}\text { Tidak } \\
\text { Membantu }\end{array}$ & 1 & 0 & 0 & \\
\hline Jumlah & & 10 & 35 & \\
\hline
\end{tabular}

Hasil pengujian beta pada biaya pembuatan prototype. Dengan pertanyaan sebagai berikut: Apakah dengan alat dengan biaya murah ini sudah dapat membantu dalam proses pendeteksian kadar udara pada lingkungan anda? Berdasarkan tabel 7 hasil persentase adalah $100 \%$. Maka dapat disimpulkan biaya prototype dinyatakan sangat membantu.
Tabel 7. Hasil pengujian beta pada biaya prototype

\begin{tabular}{|c|c|c|c|c|}
\hline Jawaban & Skor & Responden & $\begin{array}{c}\text { Jumlah } \\
\text { Skor }\end{array}$ & $\begin{array}{c}\text { Nilai } \\
\text { Persentase }\end{array}$ \\
\hline $\begin{array}{l}\text { Sangat } \\
\text { Membantu }\end{array}$ & 5 & 10 & 50 & \multirow{6}{*}{$\begin{aligned} &(50 / 50) \\
& \times 100 \% \\
&= 100 \%\end{aligned}$} \\
\hline Membantu & 4 & 0 & 0 & \\
\hline $\begin{array}{l}\text { Cukup } \\
\text { Membantu }\end{array}$ & 3 & 0 & 0 & \\
\hline $\begin{array}{l}\text { Kurang } \\
\text { Membantu }\end{array}$ & 2 & 0 & 0 & \\
\hline $\begin{array}{l}\text { Tidak } \\
\text { Membantu }\end{array}$ & 1 & 0 & 0 & \\
\hline Jumla & & 10 & 50 & \\
\hline
\end{tabular}

Hasil pengujian beta pada ukuran prototype. Dengan pertanyaan sebagai berikut: Apakah dengan alat dengan ukuran yang kecil ini sudah dapat mempermudah pendeteksian kadar udara pada lingkungan anda? Berdasarkan tabel 8 hasil persentase adalah 92\%. Maka dapat disimpulkan bahwa ukuran prototype dinyatakan sangat membantu.

Tabel 8. Hasil pengujian beta pada ukuran prototype

\begin{tabular}{|c|c|c|c|c|}
\hline Jawaban & Skor & Responden & $\begin{array}{c}\text { Jumlah } \\
\text { Skor } \\
\end{array}$ & $\begin{array}{c}\text { Nilai } \\
\text { Persentase }\end{array}$ \\
\hline $\begin{array}{l}\text { Sangat } \\
\text { Membantu }\end{array}$ & 5 & 6 & 30 & \multirow{6}{*}{$\begin{aligned} &(46 / 50) \\
& \times 100 \% \\
&=\end{aligned}$} \\
\hline Membantu & 4 & 4 & 16 & \\
\hline $\begin{array}{l}\text { Cukup } \\
\text { Membantu }\end{array}$ & 3 & 0 & 0 & \\
\hline $\begin{array}{l}\text { Kurang } \\
\text { Membantu }\end{array}$ & 2 & 0 & 0 & \\
\hline $\begin{array}{l}\text { Tidak } \\
\text { Membantu }\end{array}$ & 1 & 0 & 0 & \\
\hline Jumlah & & 10 & 46 & \\
\hline
\end{tabular}

Hasil pengujian beta pada usability. Dengan pertanyaan sebagai berikut: Apakah dengan adanya alat pendeteksi kadar udara ini dapat membantu anda untuk mengetahui kualitas udara pada lingkungan? Berdasarkan tabel 9 hasil persentase adalah 96\%. Maka dapat disimpulkan bahwa alat dapat diterima dan alat ini dinyatakan sangat membantu. 
Tabel 9. Hasil pengujian beta pada usability

\begin{tabular}{|c|c|c|c|c|}
\hline Jawaban & Skor & Responden & $\begin{array}{c}\text { Jumlah } \\
\text { Skor }\end{array}$ & $\begin{array}{c}\text { Nilai } \\
\text { Persentase }\end{array}$ \\
\hline $\begin{array}{l}\text { Sangat } \\
\text { Membantu }\end{array}$ & 5 & 8 & 40 & \multirow{6}{*}{$\begin{array}{l}(48 / 50) \\
\times 100 \% \\
=70 \%\end{array}$} \\
\hline Membantu & 4 & 2 & 8 & \\
\hline $\begin{array}{l}\text { Cukup } \\
\text { Membantu }\end{array}$ & 3 & 0 & 0 & \\
\hline $\begin{array}{l}\text { Kurang } \\
\text { Membantu }\end{array}$ & 2 & 0 & 0 & \\
\hline $\begin{array}{l}\text { Tidak } \\
\text { Membantu }\end{array}$ & 1 & 0 & 0 & \\
\hline Jumlah & & 10 & 48 & \\
\hline
\end{tabular}

Hasil pengujian beta pada tindakan antisipasi. Dengan pertanyaan sebagai berikut: Apakah alat ini dapat membantu untuk acuan sebagai pengambilan tindakan antisipasi secara dini? Berdasarkan tabel 10 hasil persentase adalah $70 \%$. Maka dapat disimpulkan bahwa pada tindakan antisipasi dinyatakan membantu.

Tabel 10. Hasil pengujian beta pada tindakan antisipasi

\begin{tabular}{|c|c|c|c|c|}
\hline Jawaban & Skor & Responden & $\begin{array}{c}\text { Jumlah } \\
\text { Skor } \\
\end{array}$ & $\begin{array}{c}\text { Nilai } \\
\text { Persentase }\end{array}$ \\
\hline $\begin{array}{l}\text { Sangat } \\
\text { Membantu }\end{array}$ & 5 & 0 & 0 & \multirow{6}{*}{$\begin{array}{r}(35 / 50) \\
\times 100 \% \\
=70 \%\end{array}$} \\
\hline Membantu & 4 & 5 & 20 & \\
\hline $\begin{array}{l}\text { Cukup } \\
\text { Membantu }\end{array}$ & 3 & 5 & 15 & \\
\hline $\begin{array}{l}\text { Kurang } \\
\text { Membantu }\end{array}$ & 2 & 0 & 0 & \\
\hline $\begin{array}{l}\text { Tidak } \\
\text { Membantu }\end{array}$ & 1 & 0 & 0 & \\
\hline Jumla & & 10 & 35 & \\
\hline
\end{tabular}

Hasil pengujian beta pada penerapan sistem. Dengan pertanyaan sebagai berikut: Menurut anda apakah alat ini akan membantu dalam proses mendeteksi kualitas udara jika di terapkan pada lingkungan perindustrian? Berdasarkan tabel 11 hasil persentase adalah $96 \%$. Maka dapat disimpulkan bahwa pada penerapan sistem dinyatakan sangat membantu.
Tabel 11. Hasil pengujian beta pada penerapan sistem

\begin{tabular}{|c|c|c|c|c|}
\hline Jawaban & Skor & Responden & $\begin{array}{c}\text { Jumlah } \\
\text { Skor }\end{array}$ & $\begin{array}{c}\text { Nilai } \\
\text { Persentase }\end{array}$ \\
\hline $\begin{array}{l}\text { Sangat } \\
\text { Membantu }\end{array}$ & 5 & 8 & 40 & \multirow{6}{*}{$\begin{array}{l}(48 / 50) \\
\times 100 \% \\
=96 \%\end{array}$} \\
\hline Membantu & 4 & 2 & 8 & \\
\hline $\begin{array}{l}\text { Cukup } \\
\text { Membantu }\end{array}$ & 3 & 0 & 0 & \\
\hline $\begin{array}{l}\text { Kurang } \\
\text { Membantu }\end{array}$ & 2 & 0 & 0 & \\
\hline $\begin{array}{l}\text { Tidak } \\
\text { Membantu }\end{array}$ & 1 & 0 & 0 & \\
\hline Jumlah & & 10 & 48 & \\
\hline
\end{tabular}

Hasil pengujian beta pada seluruh kinerja sistem. Dengan pertanyaan sebagai berikut: Bagaimana kinerja dari keseluruhan sistem? Berdasarkan tabel 12 hasil persentase adalah $90 \%$. Maka dapat disimpulkan bahwa alat dapat diterima dan dinyatakan sangat membantu.

Tabel 12. Hasil pengujian beta pada keseluruhan sistem

\begin{tabular}{|c|c|c|c|c|}
\hline Jawaban & Skor & Responden & $\begin{array}{c}\text { Jumlah } \\
\text { Skor }\end{array}$ & $\begin{array}{c}\text { Nilai } \\
\text { Persentase } \\
\end{array}$ \\
\hline $\begin{array}{l}\text { Sangat } \\
\text { Membantu }\end{array}$ & 5 & 6 & 30 & \multirow{6}{*}{$\begin{aligned} &(45 / 50) \\
& \times 100 \% \\
&= 90 \%\end{aligned}$} \\
\hline Membantu & 4 & 3 & 12 & \\
\hline $\begin{array}{l}\text { Cukup } \\
\text { Membantu }\end{array}$ & 3 & 1 & 3 & \\
\hline $\begin{array}{l}\text { Kurang } \\
\text { Membantu }\end{array}$ & 2 & 0 & 0 & \\
\hline $\begin{array}{l}\text { Tidak } \\
\text { Membantu }\end{array}$ & 1 & 0 & 0 & \\
\hline Jumlah & & 10 & 45 & \\
\hline
\end{tabular}

Hasil pengujian Beta secara keseluruhan pada Alat Pendeteksi Kadar Udara Berbasis Arduino Uno dengan menggunakan rumus (2)

$$
\begin{aligned}
\mathrm{Y} & =(47+50+34+35+50+46+48+32+48+45) / 10 \\
& =43,5 \\
& =43,5 / 50 \times 100 \%=87,0 \%
\end{aligned}
$$


Maka dapat disimpulkan bahwa alat pendeteksi kadar udara berbasis Arduino Uno ini dapat diterima dan dapat membantu dengan persentase $87,0 \%$. Sesuai dengan skala persentase yang telah ditentukan, persentase $87,0 \%$ terdapat grade nilai Sangat Membantu yaitu antara $81 \%-100 \%$.

\section{KESIMPULAN}

Untuk membuat alat pendeteksi kadar udara berbasis Arduino Uno, dibutuhkan 4 komponen utama yaitu, Arduino Uno sebagai mikrokontroler utama perangkat keras, Sensor MQ7 sebagai sensor pendeteksi karbon monoksida, sensor GP2Y1010AU0F sebagai sensor debu, sensor DHT11 sebagai sensor suhu, dan LCD 16x2 sebagai tampilan nilai pada pembacaan sensor.

Berdasarkan hasil dari pengujian yang telah dilakukan dari tahap pertama hingga tahap kelima dapat disimpulkan bahwa pendeteksi kadar udara ini dapat berfungsi dengan baik, dimana masing - masing alat dapat berfungsi sebagaimana mestinya.

\section{SARAN}

Diharapkan untuk mendapatkan hasil yang lebih baik, sensor dapat diganti dengan kualitas yang baik. Agar sistem ini dapat dijadikan sebagai acuan atau referensi penelitian di bidang teknik dan informatika. Penelitian lebih lanjut diharapkan agar dapat mengembangkan alat ini dengan menambah sensor dan mengubah sistem menjadi Internet of Things.

\section{DAFTAR PUSTAKA}

Artanto, D. (2012). Interaksi Arduino dan LabVIEW. Jakarta: PT Elex Media Komputindo.

Atmaja, David Agung Nadya. "Rancang Bangun Pemantauan Suhu Beserta Kualitas Udara Pada Terminal Arjosari Malang Melalui Website Berbasis Arduino." JATI (Jurnal Mahasiswa Teknik Informatika) 2.1 (2018): 380-387.

Dinata, Y. M. (2016). Arduino Itu Pintar. Elex Media Komputindo.

Halizah, N., Zahro, H. Z., \& Rudhistiar, D. (2021). Rancang Bangun Sistem Monitoring Polusi Udara Pada Budidaya Tanaman Sayur Hidroponik. JATI (Jurnal Mahasiswa Teknik Informatika), 5(1), 308314.

Kadir, A. (2016). Simulasi Arduino. Elex Media Komputindo.

Kaunang, F. J., Karim, A., Simarmata, J., Iskandar, A., Ardiana, D. P. Y., Septarini, R. S., ... \& Widyastuti, R. D. (2021). Konsep Teknologi Informasi. Yayasan Kita Menulis.

Kusumah, H., Handayani, I., \& Susilo, P. (2018). Prototipe Monitoring Kualitas Udara Ruangan Berbasis Awan Adafruit SGP30 Air Quality Sensor. Technomedia Journal, 3(1), 121-132.

Kusumaningtyas, M. A., Bramawanto, R., Daulat, A., \& Pranowo, W. S. (2014). Kualitas perairan Natuna pada musim transisi. DEPIK Jurnal Ilmu-Ilmu Perairan, Pesisir dan Perikanan, 3(1).

McRoberts, M. (2011). Beginning Arduino. Apress.

Orlowski, C. (2020). Management of IOT Open Data Projects in Smart Cities. Academic Press.

Sakti, S. P. (2017). Pengantar Teknologi Sensor: Prinsip Dasar Sensor Besaran Mekanik. Universitas Brawijaya Press.

Tarigan, R. (2016). Metode Penyusunan Prototipe Denah Seri Pemrograman, Perencanaan dan Perancangan Arsitektur. Penerbit Andi.

Warsiti, W., Risman, R., \& Ristiawan, A. (2020). Kajian Kualitas Ambien Udara di Kota Semarang (Studi Kasus: Jalan Setiabudi Dan Jalan Anton Sujarwo). Wahana Teknik Sipil: Jurnal Pengembangan Teknik Sipil, 25(2), 148-157.

Wasista, S., Setiawardhana, D. A. S., \& Susanto, E. (2019). Aplikasi Internet of Things (IoT) dengan Arduino dan Android. Deepublish.

\section{UCAPAN TERIMA KASIH}

Publikasi ini dibiayai oleh Direktorat Riset dan Pengabdian Masyarakat Direktorat Jenderal Penguatan Riset dan Pengembangan Kementerian Kementerian Pendidikan, Kebudayaan, Riset, dan Teknologi Republik Indonesia dengan Kontrak Penelitian Tahun Anggaran 2021. 